\title{
Insights from the 34th Biennial CAO Congress 2015
}

\author{
Pauline Blachford
}

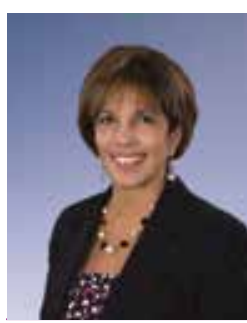

Pauline Blachford consults optometrists on how to reduce unbooked appointments, increase eyewear sales, and improve employee productivity. She has abundant experience in the eye health industry, including 17 years at White Rock Optometry in BC. Pauline frequently presents at optometry conferences and is a regular columnist for the CJO. For more information, visit paulineblachford.com.

Tnteresting new people, dynamic presentations, a charming city, and a pound and a half of Llobster! Unless you're allergic to shellfish, it doesn't get much better than that.

I had a great time at the CAO Congress in July and found it very intellectually stimulating.

In this article, I share some of the insights I gleaned from attending the sessions, touring the Optofair, chatting with new people I met, and giving two presentations to fun and engaged audiences. Given that I consult optometrists on how to manage and grow their practices, I was particularly alert to information that could help optometrists achieve their business goals and live fulfilling professional lives.

\section{BUILD YOUR TEAM}

I was pleased to see that Crystal Clowater presented on employee engagement and team productivity, as these are topics I often address with my clients. In her presentation "The Spirit of Teamwork," Crystal, who is the office manager for Spectrum Vision Clinic in New Brunswick, cautioned that when staff members become trapped in task-oriented patterns, they become less creative and lose sight of their role within the larger team. This is when conflicts arise.

Crystal encouraged her audience to create work cultures in which team members love their work, understand their role, take pride in what they do, and receive praise for their contributions. She noted that businesses that build this type of work culture experience less employee turnover. ${ }^{1}$

\section{IF YOU RECOMMEND IT, SELL IT}

As I toured the Optofair, I was reminded of a recommendation I often give my clients: if you find yourself frequently recommending a product-for example, omega 3 supplements or Systane eye drops-you should probably be selling that product.

I hold this belief for two reasons. First, as patients come to realize that optometrists do a whole lot more than test vision and prescribe lenses, it's only natural that they come to expect optometrists to offer the products that support the other services that optometrists provide. "If my optometrist can help me prevent glaucoma disease or treat my dry eyes, why can't I purchase the products that will help me avoid or treat those diseases from her clinic?"

The second reason is psychological. We want our patients to view our clinic as a onestop-shop for all their vision health needs, from having their eyes examined, to receiving a prescription, to purchasing the product that has been prescribed. If you don't want your patients taking their prescription elsewhere to purchase their eyeglasses, why would you reinforce such behaviour when it comes to purchasing the other products you prescribe? 


\section{BE PRESENT AND LAUGH MORE}

I attended two presentations related to improving clarity of mind and reducing stress, important topics for individuals who juggle the responsibilities of being a doctor and managing a business (not to mention personal obligations). In the first of these presentations, Dr. Bill Cook posited that we spend $40 \%$ of our time thinking about the past, $50 \%$ thinking about the future, and only $10 \%$ living in the present. This leads to stressing over what has passed and pondering future events that may never occur, while missing out on the realities and joys of today. Dr. Cook told us that learning to spend more time in the present (being "mindful") requires practice, which is done through meditating. While I am not experienced in mindfulness or meditation, it's something I hear more and more about, and there is no shortage of research on the health benefits. ${ }^{2}$

In the second presentation entitled "Laughter for the Health of It," Dr. Barbara Cull-Wilby maintained that laughing can lead to happiness, gratitude, and radiance. If you can't find time to watch reruns of Friends, Dr. Cull-Wilby says to fake-laugh as a means of getting started. While it may sound too simple to be true, if Dr. Cull-Wilby is correct about the benefits, maybe laughter is the best medicine.

\section{EMPOWER YOUR LINCHPINS}

Every time I present at an optometry conference, I marvel at the number of highly engaged optometric staff in the audience. My audiences at this congress were no exception. Most of the attendees took notes and participated in my presentations, and I received a number of thoughtful questions during my Q \& As. After my presentations were over, some attendees approached me to ask specific questions about how they could help their clinics reduce unbooked appointments and increase eyewear sales.

I love interacting with these types of people. I refer to them as "linchpins," a term coined by the business thought leader, Seth Godin. A linchpin is someone who does not just complete assigned tasks, but rather uses her unique skills and abilities to identify and execute potential improvements. If you have a linchpin on your staff, seek her insight, empower her to propose and implement new ideas, and keep her stimulated with more training and learning opportunities.

\section{LOOK TO THE FUTURE}

In helping my clients fill their schedules, eventually we are forced to consider what happens when the clinic's schedule is fully booked. "If it takes a new client more than two weeks to get an appointment," I caution, "you're building the client base of the clinic down the street." Taking on an associate (or another associate) is one way to solve this "problem." But deciding to do so is not a decision to take lightly. Quality control, mentorship, and other managerial responsibilities are time consuming, and they are tasks that some people just don't like doing. But new associates can also provide a host of benefits, including increased revenue, an influx of energy and new ideas, and a wonderful opportunity for experienced optometrists to pass on their wisdom to the next generation.

For those who do decide to take on a new associate, the future is bright. During the congress, I had the pleasure of meeting Samantha Menzies, Phyllis Ho, Jeffrey Lam, Jonathan Dinh, and Abraham Yuen, all of whom are recent graduates or current students at the University of Waterloo, School of Optometry \& Vision Science. They are mature, intelligent, keen, and fun to be around. The clinics that scoop up these young optometrists will be lucky to have them. And I look forward to working with them in the future.

In conclusion, it was a thought-provoking and inspiring conference. Big thanks to the cochairs, Dr. Lil Linton and Dr. Ron Harding, and the Local Arrangements Committee, which included local optometrists Drs. Amanda Bartlett, Marisa Blanchard, Lisa Bock, Amanda Brown, Les Clements, Pat Clements, Brian Dalrymple, Neema Patel, Harry Bohnsack, Tara McCarthy, Mel Soicher, Tom Hickey, Mark Inman, Michelle Lane, Richard Lee, Michele Leger, Bronwyn Mulherin, Calvin Smith, and Tim Wiley. Mimi McLaughlin and Nettie Whitlock worked closely 
with the CAO staff and the Congress chairs/Local Arrangements Committee. Thank you as well to the CAO staff which included Laurie Clement, Debra Yearwood, Catherine Heinmiller, Doug Dean, Helen Bouchard, and Danielle Paquette.

I look forward to doing it again in Ottawa in 2017.

\section{RREFERENCES}

1. For more information on how to reduce employee turnover, see my article "Reducing Employee Turnover" in the Canadian Journal of Optometry 2014;76(2):29.

2. For a synopsis, see Time Magazine cover stories "The Science of Meditation” (August 2003) and "The Mindful Revolution" (February 2014).

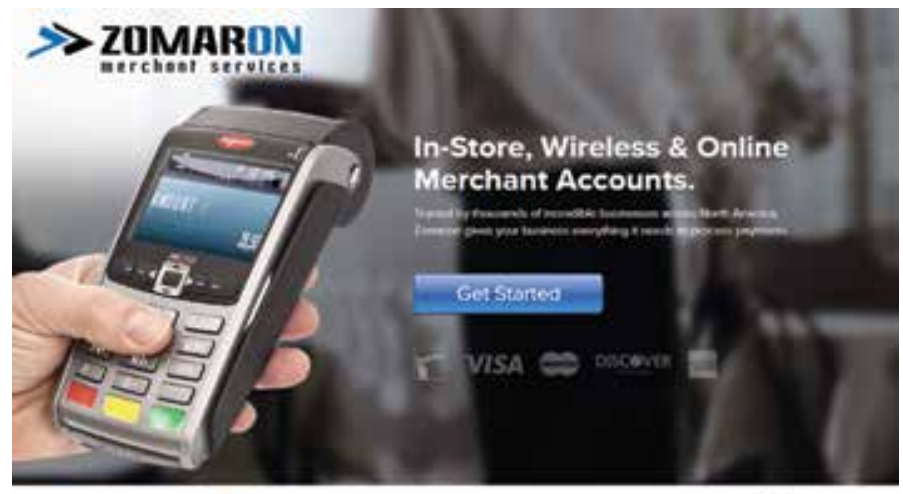

ZOMARON is the preferred provider of merchant services for the

Canadian Association of Optometrists.

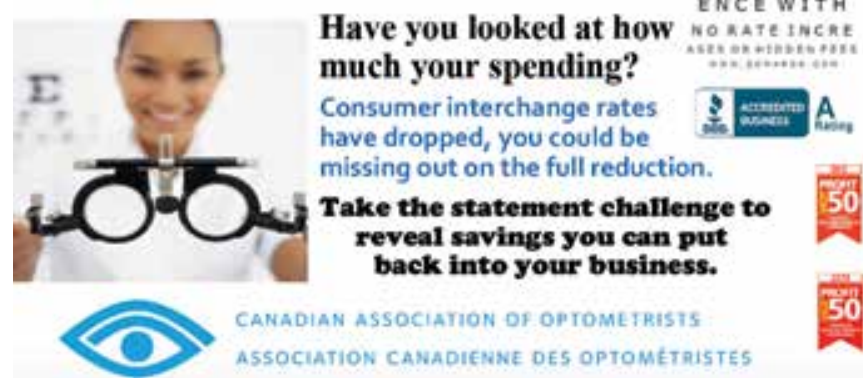

For more information and to apply, contact ZOMARON at 1-888-900-9192 ext. 766 or email CAO@zomaron.com www.zomaron.com

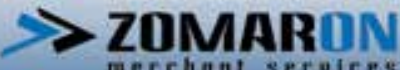

